\title{
Nitric Oxide: Friend or Foe in Cancer Chemotherapy and Drug Resistance: A Perspective
}

Birandra K Sinha*

Immunity, Inflammation and Disease Laboratory, National Institute of Environmental Health Sciences, NIH, Research Triangle Park, North Carolina, USA

\begin{abstract}
A successful treatment of cancers in the clinic has been difficult to achieve because of the emergence of drug resistant tumor cells. While various approaches have been tried to overcome multi-drug resistance, it has remained a major road block in achieving complete success in the clinic. Extensive research has identified various mechanisms, including overexpression of P-glycoprotein 170, modifications in activating or detoxification enzymes (phase I and II enzymes), and mutation and/or decreases in target enzymes in cancer cells. However, nitric oxide and/or nitric oxide-related species have not been considered an important player in cancer treatment and or drug resistance. Here, we examine the significance of nitric oxide in the treatment and resistance mechanisms of various anticancer drugs. Furthermore, we describe the significance of recently reported effects of nitric oxide on topoisomerases and the development of resistance to topoisomerase-poisons in tumor cells.
\end{abstract}

Keywords: Nitric oxide; Chemotherapy; Anticancer drugs; Topoisomerases; Drug resistance

\section{Introduction}

The emergence of cancer cells resistant to chemotherapy drugs has been a major problem in successful treatment of human tumors in the clinic [1-4]. A flurry of research both in the laboratory and in the clinic have identified several mechanisms to explain this resistance [1-4]. One of the most important observations has been the identification of p-170 glycoprotein (pgp), which was overexpressed in resistant tumor cells following drug treatment. Subsequently, it was shown that p-170 glycoprotein was involved in removing drugs from the cancer cells in an energy-dependent manner. Furthermore, it was soon discovered that this protein was also involved in the removal of many drugs that were structurally very different from one another. Rapid progress has identified many other mechanisms of cancer drug resistance, including mutation of certain genes (e.g., p53, topoisomerases), decrease in activity of proteins (e.g., topoisomerases) and modification of drug metabolism and detoxification (phase I and II) enzymes [5-7]. While significant progress has been made towards understanding the mechanisms of cancer drug resistance and we can now adequately explain mechanisms of resistance to ionizing radiation and many commonly utilized chemotherapeutic drugs in the laboratory, significant problems remain in the clinic, as modulation of these pathways and enzymes has not been very successful in curing cancers or alleviating human suffering.

Cancers are extremely complicated and involve many interrelated pathways; no single mechanism of resistance is expected to explain all of them. Recent studies suggest that nitric oxide ("NO) may play an important role in the treatment of human cancers. ${ }^{\mathrm{NO}} \mathrm{O}$ is a short-lived free radical molecule that easily diffuses in tissues. It is an important cellular messenger and plays a role in many important physiological functions, including vasodilatation, apoptosis, and the innate immune response. It is believed that many of the actions of * $\mathrm{NO}$ as a signalling molecule results from its interactions with the heme moiety of the soluble guanyl cyclase, causing the activation and production of second messenger cyclic GMP $[8,9]$. Recent studies further suggest that many of the actions of nitric oxide results from formation of its reactive metabolites $\left(\mathrm{NO}^{+}, \mathrm{N}_{2} \mathrm{O}_{3}, \mathrm{OONO}\right)$ and introduction of nitroso groups onto a reactive sulfhydryl group of a protein to form an S-nitrosothiol (-SNO) [10-12]. This process of modulation by nitric oxide is commonly known as S-nitrosylation or S-nitrosation, and it is believed that nitrosation of proteins is involved in cell signalling.
Nitric oxide is also implicated in cancer cell killing, cancer progression and metastasis and poor survival [13-17]. A poor clinical outcome is believed to result from "NO-induced rapid tumor growth, resulting in hypoxia, nutrient deprivation, poor drug delivery, and selection for drug-resistant tumor cells. In vivo, "NO is formed from L-arginine by nitric oxide synthase (NOS). Three forms of NOS have been identified, including neuronal (nNOS), endothelial (eNOS), and a $\mathrm{Ca}^{2+}$-independent inducible isoform (iNOS). High expression of iNOS and increased production of ${ }^{\circ} \mathrm{NO}$ have been described in many human tumors, including breast, prostate and colorectal cancers [17-20]. Increased and continuous generation of ${ }^{*} \mathrm{NO}$ plays a significant role in the regulation of cancer cell progression and carcinogenesis. Hibbs et al. $[21,22]$ and Stuehr and Nathan [23] have shown that co-culturing of leukemia L1210 cells with activated peritoneal macrophages results in the inhibition of L1210 cell proliferation which is correlated with nitrite formation. Inhibitors of NOS (L-NAME) and myoglobin, a scavenger of ${ }^{*} \mathrm{NO}_{2}$ were effective in inhibiting cell killing actions of the activated macrophages, suggesting that "NO is responsible for the killing actions of activated macrophages towards cancer cells.

It is believed that DNA damage and apoptosis induced by ${ }^{*} \mathrm{NO}$ in tumor cells cause tumor cell death; studies are needed to explore processes to deliver the highest concentrations of * $\mathrm{NO}$ in tumor cells using NO-donors as single chemotherapeutic agents or in combination with other chemotherapeutic agents. While significant progress has been made in the last decade, the role of ${ }^{*} \mathrm{NO} /{ }^{*} \mathrm{NO}$-related species remains poorly understood in chemotherapy and drug resistance. Here, we review the role of ${ }^{*} \mathrm{NO} /{ }^{*} \mathrm{NO}$-related species in cancer chemotherapy

*Corresponding author: Sinha BK, Immunity, Inflammation and Disease Laboratory National Institute of Environmental Health Sciences, NIH, Research Triangle Park, North Carolina, USA, Tel: +919-541-4751; E-mail: sinha1@niehs.nih.gov

Received September 29, 2016; Accepted October 26, 2016; Published October 28,2016

Citation: Sinha BK (2016) Nitric Oxide: Friend or Foe in Cancer Chemotherapy and Drug Resistance: A Perspective. J Cancer Sci Ther 8: 244-251. doi: 10.4172/19485956.1000421

Copyright: ( 2016 Sinha BK. This is an open-access article distributed under the terms of the Creative Commons Attribution License, which permits unrestricted use, distribution, and reproduction in any medium, provided the original author and source are credited. 
and critically examine their roles in the emergence of cancer cell resistance to various drugs.

\section{Nitric Oxide: A Friend in Chemotherapy}

\section{Nitric oxide as a single agent}

Because $\mathrm{NO}$ is a gas and forms many reactive metabolites in the presence of molecular oxygen, it is difficult to deliver and study the biological effects of "NO in tumor cells in vivo. To overcome these problems and to deliver "NO in tumor cells in vivo in a consistent manner, many chemicals have been synthesized that release "NO at physiological $\mathrm{pH}$ (at various half-lives from minutes to days) or undergo bio-activation in vivo to release nitric oxide. Maragos et al. [24] were the first to report that "NO released from nitric oxidedonors was inhibitory to A375 human melanoma tumor cells in vitro. A structure activity relationship study indicated that compounds that released "NO slowly were more toxic to cells than those compounds that released "NO rapidly, suggesting that sustained exposure to "NO for a longer time is more damaging to tumor cells. Thus, both the amount and exposure time were critical for cell cytotoxicity. Several NO-donors have now been evaluated as anticancer agents in various tumor cell lines, including organic nitrite, glyceryl nitrite, nitrosothiols and diazeniumdiolates. Several excellent reviews are already available highlighting the importance of NO-donors as anticancer agents [15,2529]. Therefore, these are not focused on in detail in this review.

Wink et al. [30] have shown that certain NO-donors sensitized cisplatin cytotoxicity in Chinese hamster ovary cells. High concentrations of "NO released from these NO-donors have been found to induce apoptosis and inhibition of cell growth. These NO-donors were found to be effective in inducing growth inhibition in both wild-type p53containing and p53-deficient cell types. However, it is interesting to note that some differences in toxicity were observed, i.e., p53-deficient SW620 cells were more sensitive than HCT116, wild-type p53containing cells. In a series of cell lines derived from colon cancer, the status of cyclooxygenase and/or activity was not important for "NOinduced cell death [31]

Because *NO and/or reactive species derived from it react with cellular components and cause damage to both normal cells and tumor cells, it is necessary to deliver NO-releasing toxic compounds directly to tumor cells in vivo (target specificity). Various prodrugcontaining "NO moieties have therefore, been synthesized. One such approach utilized synthesis of esterase-sensitive nitric oxide donors of the diazeniumdiolates [32]. These compounds were found to be active against leukemia cells, but only after releasing ${ }^{*} \mathrm{NO}$ via activation by certain tumor cell esterases.

In keeping with the idea of selectively destroying tumor cells by "NO without affecting normal cells, Shami et al. [33] designed and synthesized various prodrugs for $\mathrm{NO}$-donors containing $\mathrm{O}^{2}$-aryl diazeniumdiolates. One such compound JS- $\mathrm{K}\left(\mathrm{O}^{2}-(2,4\right.$-dinitrophenyl) 1-[(4-ethoxycarbonyl)piperazin-1-yl]diazen-1-ium-1,2-diolate) was found to be an extremely active anticancer agent against human HL60 leukemia cells in vitro and reduced the growth of subcutaneously implanted HL60 cells in nude mice [33]. JS-K is active against human non-small cell lung cancer cells [34] and induces apoptosis in human multiple myeloma cells both in vitro and in vivo [35]. It was found that JS-K was activated following reactions with glutathione to produce "NO in vivo catalyzed by glutathione S-transferase [33]. Shami et al. [33,36-38] have extensively characterized interactions of JS-K with glutathione/glutathione S-transferase and have found that the GST- $\mu$ form is the major enzyme responsible for releasing ${ }^{*} \mathrm{NO}$ in vivo. Targeting of tumors by ${ }^{*} \mathrm{NO}$ was also achieved with glycol-
S-nitrosothiols (sugar-SNAP) that resulted from enhanced uptake of saccharides in tumor cells and delivering ${ }^{*} \mathrm{NO}$ directly to tumor cells (34). Reynolds et al. [29] have reported synthesis of polysaccharidebased dextran thiomers which contained covalently attached NOdonors. They found that these NO-donor compounds were stable and quantitatively released "NO under normal physiological conditions. While these compounds were found to be extremely effective in killing bacteria, no data is currently available about their cytotoxic profiles in human tumor cells either in vitro or in vivo.

\section{Nitric oxide in combination with antitumor agents}

Since the early observations of Wink et al. [30] showing that certain NO-donors enhanced the cytotoxicity of cis-platin in Chinese Hamster V79 lung fibroblast cells, extensive research has suggested that the delivery of "NO via NO-donors has been beneficial and/or synergistic with various anticancer drugs in killing tumor cells in vitro and in animal models [15,25-29]. Interestingly, not all nitric oxide donors are effective in this sensitization of cytotoxicity as it was found to depend upon both the flux of "NO and the reactive species formed. Furthermore, the sensitization to cis-platin cytotoxicity was shortlived [30]. Since these important observations, a significant amount of research has been carried out showing sensitization to cis-platin and other Pt-based drugs by NO-donors in tumor cells [28,39-41] and in vivo in nude mice. An NO-donor derived from aspirin (NCX-4016) was also effective in sensitizing cisplatin cytotoxicity in both sensitive and cisplatin-resistant cell lines [40]. It is believed that decreases in cellular glutathione played a significant role in the mechanisms of this sensitization [40]. Combinations of NCS-4040, an NO/NSAID, and oxalplatin were also found to be effective in vivo in nude mouse models against colon cancer cells [42].

It is important for "NO delivery in vivo to be selective; one such approach involves gene therapy with iNOS in tumor cells. A successful therapy has been reported using gene transfer with iNOS and cisplatin against prostate, colon and sarcoma tumors in vivo [43]. Targeted "NO has also been shown to significantly enhance the sensitivity of carmustin (BCNU) and temzolomide against glioma cells, and which was suggested to result from altered p53 and $\mathrm{O}^{6}$-methylguanine-DNA methyltransferase activities in the tumor cells [44].

A number of studies have shown that certain NO-donors when combined with doxorubicin are also effective against tumors $[45,46]$. Furthermore, certain NO-donors e.g. DETA-NO, and nitroglycerin (GTN), were effective in enhancing doxorubicin cytotoxicity and reversing hypoxia-induced resistance to doxorubicin [47]. "NO was shown to enhance doxorubicin cytotoxicity in a mouse model against prostate tumors as well as against breast MDA-MB-231 cells in a spheroid model [46]. This is in contrast to our studies with PPNO, an NO-donor, which had no effect on doxorubicin cytotoxicity against human breast MCF-7 and colon HT-29 cell lines in vitro [48]. We also found that ${ }^{*} \mathrm{NO}$ did not modulate the toxicity of doxorubicin against human melanoma cells [49]. This suggests that PPNO, which has a short half-life, is not an effective modulator of doxorubicin cytotoxicity.

Because "NO modulates the activities of various anticancer drugs under hypoxic conditions, the application or use of NOdonors in enhancing chemotherapy in solid tumors is becoming increasingly important. Solid tumors in general are hypoxic due to poor intratumor blood flow. Under hypoxic conditions, tumors have been shown to accumulate hypoxia-inducible factors (HIF) due to lack of prolyl hydroxylase-dependent ubiquitination and degradation of HIF1- $\alpha[50,51]$. 
While studies show that "NO delivered via NO-donors sensitizes/ enhances cis-platin activity both in vitro and in vivo, several observations indicate opposite effects of *NO in the development of resistance to cis-platin in several human tumor cells, including lung, colon and melanoma [52,53]. It has been shown that ${ }^{*} \mathrm{NO}$ nitrosylates bcl2 protein, which inhibits ubiquitination and proteosomaldependent degradation of bcl2 protein, resulting in its stabilization [52]. This stabilization then inhibits apoptosis and induces cis-platin resistance. Furthermore, it has been shown that both intracellularly and exogenously generated "NO (delivered via an NO-donor) in human melanoma tumor cells induces significant nitrosylation of various cellular proteins, including caspase-3 and prolyl-hydroxylase-2 [53]. Prolyl-hydroxylase-2 is responsible for the hydroxylation of hypoxia inducible factor-1 $\alpha$ (HIF1- $\alpha$ ), leading to the degradation of HIF-1 $\alpha$ via a proteosomal pathway. Alternation/inhibition in the activities of these enzymes is believed to cause induction of cis-platin resistance in melanoma tumor cells.

These opposite observations should be properly addressed. Are there large differences in the activity of "NO due to concentration differences of NO-donors used in these experiments? Does the selection of NO-donors or use of certain tumor cell lines influence the results? The observations that endogenously formed "NO in human lung and melanoma cells causes resistance to cis-platin would suggest that low levels of ${ }^{*} \mathrm{NO}$ (as tumor cells in general do not generate large amounts of "NO as formed in macrophages from the induction of iNOS) is sufficient to induce resistance to cis-platin. However, ${ }^{*} \mathrm{NO}$ is continuously generated in these tumor cells, which may act differently than a bolus injection of *NO when delivered via an NO-donor only for a short duration. Whatever the reasons they must be resolved with further studies.

A part of the conflicting effects of "NO on sensitization or emergence of drug resistant cells may simply be due to the known dosedependent dual effects of "NO in cancer cell biology [54-56]. Nitric oxide can either stabilize or induce degradation of HIF-1 $\alpha[57,58]$. It has been observed that ${ }^{*} \mathrm{NO}$ can nitrosylate HIF-1 1 directly, resulting in its stabilization, and that stabilization is independent of the prolyl hydroxylase-dependent mechanism. It has been shown that the effects of ${ }^{*} \mathrm{NO}$ on HIF-1 $\alpha$ are biphasic: At high ${ }^{*} \mathrm{NO}$ concentrations $(>1.0 \mu \mathrm{M})$ HIF-1 $1 \alpha$ is stabilized, and at lower concentrations $(<400 \mathrm{nM})$ HIF- $1 \alpha$ is rapidly destroyed [57]. It would appear then that depending upon the concentrations of * $\mathrm{NO}$ (thus, the concentrations of NO-donors) used to evaluate the cytotoxicity of cis-platin or doxorubicin in tumor cells, one can get either sensitization or resistance to the drug.

\section{Nitric Oxide: A Foe in Cancer Chemotherapy}

While the role of ${ }^{*} \mathrm{NO}$ and its related species in cancer drug resistance is not known, there now exists some evidence that ${ }^{*} \mathrm{NO}$ and its related species plays a significant role in the development of drug resistance and in the selection of resistant tumor cells in vivo.

\section{Topoisomerase-based resistance induced by nitric oxide}

A number of clinically active drugs interact with topoisomerases (I and II), which are nuclear enzymes responsible for maintaining the topology and functions of DNA [59-63]. It has been shown that interference with the functions of these enzymes results in inhibition of cell synthesis and ultimately cellular death. Resistance to these topopoisons results from mutation of the topo gene, and/or decreases in activity of the proteins [59-63]. We have found that "NO nitrosylates both topoisomerase I and II in human breast MCF-7 tumor and colon tumor HT-29 cells when treated with PPNO, an NO-donor $[48,64]$. We have recently reported that nitrosylation of topoisomerase I leads to proteosomal degradation with time and causes significant resistance to camptothecin, a topo I-specific drug [64]. Interestingly, this nitrosylation of the protein had no significant effect upon the activity of the protein nor did it decrease topo I-dependent DNA damage in tumor cells. Resistance to camptothecin was found to result from ${ }^{*} \mathrm{NO}$ -induced wtp53-dependent upregulation/stabilization of bcl2 protein in MCF-7 cells, as no resistance was observed in HT-29 tumor cells (mutant 53-containing cells) [64].

We have also found that "NO related species react directly with etoposide (a topoisomerase II-poison) or etoposide-derived radical. The products of this reaction were found to be significantly less toxic to tumor cells than the parent drug [65]. Furthermore, we have recently shown that "NO also causes nitrosylation of topoisomerase II-SH functional groups in cells [48]. Unlike, topoisomerase I, nitrosylation of topoisomerase II leads to a decrease in its catalytic and relaxation activities both in vitro and in tumor cells [48]. An "NO-induced decrease in topoisomerase II activity leads to a decrease in DNA damage and induction of significant resistance to etoposide, m-AMSA and XK469 in MCF-7 breast tumor cells. It is interesting to note that while ${ }^{*} \mathrm{NO}$ (or its related species) was able to nitrosylate active - $\mathrm{SH}$ functions of both topoisomerase I and II similarly, only the activity of topoisomerase II was significantly compromised, resulting in less DNA damage. While the exact reason (s) for this is not known, we have recently found that ${ }^{*} \mathrm{NO}$ significantly inhibits ATPase activity in general (manuscript in submission; there is no ATP binding site in topoisomerase I and it does not require ATP for its activity). Thus, this inhibition of ATPase activity results in a decrease in topoisomerase II activity and decrease DNA damage as observed in our studies.

Our observations that ${ }^{*} \mathrm{NO}$ inhibits decatenation reactions of topoisomerase II without inducing DNA cleavage [48] present another possible mechanism for ${ }^{*} \mathrm{NO}$-induced tumor cell killing. Such compounds are known as catalytic inhibitors and including ICRF-193 and related bisdioxopiperazines. These drugs inhibit double-strand break formation, and activate the decatenation checkpoint $[66,67]$ Impaired decatenation checkpoints have been reported in various bladder and lung cancer cell lines. Nakagawa et al. [68] have shown that certain lung tumor cell line with deficient decatenation checkpoints were highly sensitive to ICRF-193, suggesting that it is possible to design a catalytic inhibitor as an anticancer agent to target specifically altered tumors. Thus, based upon our observations that "NO is a topo II catalytic inhibitor, an appropriate nitric oxide donor can be designed as an anticancer drug for appropriate tumors in the clinic.

\section{Miscellaneous mechanisms of resistance induced by nitric oxide}

It has been reported that mammalian cells incubated with excess "NO accumulate p53 protein, but concomitantly this p53 loses its capacity for binding to its DNA consensus sequence. Chazote-Aubert et al. $[69,70]$ have shown that treating wild-type p53-containing MCF-7 cells with S-nitrosoglutathione resulted in the nitration of p53 protein. Furthermore, treatment of MCF-7 tumor cells with S-nitroso$\mathrm{N}$-acetyl-DL-penicillamine ( $2 \mathrm{mM}$ to $5 \mathrm{mM}$ ) or S-nitroso-glutathione $(1 \mathrm{mM}$ to $2 \mathrm{mM}$ ) resulted in a rapid accumulation of $\mathrm{p} 53$ protein in the nuclei. This 553 protein, however, possessed a significantly decreased activity of specific DNA binding, suggesting modification/alteration of the protein. In contrast, lower concentrations of NO-donors $(0.25 \mathrm{mM}$ to $0.5 \mathrm{mM}$ ) stimulated p53 accumulation as well as its DNA binding activity. These results suggest that excess ${ }^{*} \mathrm{NO}$ produced in inflamed tissues or in tumor cells could lead to impaired p53 functions that may 
play a significant role in selection of resistant tumor cells in vivo or affect DNA repair in tumor cells.

Studies have shown that $\mathrm{NO}$ modulates the activity of various DNA repair proteins [71-73], most notably DNA-PKcs, an enzyme responsible for repairing both single and double-strand breaks [73]. This NO-dependent upregulation of DNA-PKcs activity afforded significant protection from several DNA-damaging agents, including, $\mathrm{X}$-ray radiation, cis-platin, doxorubicin and bleomycin [73]. Xu et al. [73] have shown that both endogenously and exogenously generated "NO induced upregulation of DNA-PKcs in several human tumor cells, including lung A549 and glioma A172 tumor cells, and ultimately caused resistance to ionizing radiation and cis-platin. Induction of DNA-PKcs by "NO was clearly shown to cause increased repair of DNA-double strand breaks in these tumor cells. Liu and Xu [60] have further shown that endogenously generated "NO in MCF-7 cells also upregulates other DNA repair proteins, e.g., topoisomerase II and Rad2, in addition to DNA-PKcs and HIF-1a.

Studies from various laboratories indicate that "NO nitrosylates certain drug target proteins, altering their activity and/or inducing their degradation $[11,52,74,75]$. These events ultimately can induce resistance to drugs in vitro and in the clinic. ${ }^{*} \mathrm{NO}$ has been shown to induce cis-platin resistance in human melanoma tumor cells by nitrosating bcl2 protein, causing its stabilization, and inhibiting cis-platin-induced apoptosis in tumor cells [52]. In this regard, Wongvaranon et al. [76] have shown that long term exposure (7-14 days) to "NO (via an NO-donor) resulted in resistance to cis-platin, doxorubicin and etoposide in lung NCI-H292 tumor cells. It was shown that the induction of resistance to these drugs was due to an increase in cellular cavolin-1 and bcl2 proteins and up-regulation of activated protein kinase B (AKT). ${ }^{*} \mathrm{NO}$ treatment did not result in a stable drug-resistant phenotype and resistance was reversible when cells were cultured in the absence of ${ }^{*} \mathrm{NO}$ [76].

Glynn et al. [17] have shown that increased $\mathrm{NOS}_{2}$ (iNOS) in women with ER negative breast tumors may be linked to poor survival in the clinic. Heinecke et al. [77] have further shown that stimulation of $\mathrm{NOS}_{2}$, such as that found in tumors contaminated by circulating macrophages or during hypoxia, induces the upregulation of NOtargeted biomarkers, e.g., IL-6, IL-8, calcium binding protein S-100A8, and tissue inhibitor matrix metalloproteinase-1. These bio-markers have been suggested to promote cell survival and cancer progression. Using MDA-231 breast cancer cells as a model in vitro and in nude mice, these authors have shown that increased "NO generation leads to altered cell migration. More importantly, it also leads to the development of resistance to taxol, a most commonly used anticancer drug for the treatment of breast cancer in the clinic. It is suggested that interferon (IFN-Y) may be responsible, in part, for these effects, as IFN- $\Upsilon$ was found to induced NOS, ${ }^{,} \mathrm{NO}$ formation, and IL- 6 formation in MDA-231 cells. IFN- $\Upsilon$ has been linked to more aggressive, clinically resistant tumors $[78,79]$.

One of the major problems in assessing the proof of mechanism in vivo is the complexity of living cells and humans. In assessing a mechanism of multi-drug resistance, it was possible to insert an mdr1 gene into tumor cells and assess the effects on cytotoxicity of various drugs of multi-drug resistance. However, no such experiments have been carried out with the iNOS gene. The situation is even more complex because the effective concentrations of ${ }^{*} \mathrm{NO}$ required to induce resistance in tumor cells and in vivo is not clear now. In a series of publications, Radosevich et al. [80-82] have exposed human breast cancer cells to increasing concentrations of "NO (via an NO-donor,
DETA-NONOate) and examined the resulting biochemical and genetic changes associated with $\mathrm{NO}$-adapted (resistant) cells. It was found that these ${ }^{*} \mathrm{NO}$-adapted cells grew faster and were significantly more aggressive. These cells expressed higher amounts of p53 protein and showed mutation of the 53 gene. Most interestingly, these cells showed up-regulation of GST-pi and were resistance to both X-ray and UVradiation. Furthermore, these authors have reported that adapted cells also used more anaerobic glycolysis than the parent cells [82]. However, it is not known whether NO-adapted breast cancer cells maintained these biochemical changes when cultured under normal conditions in the absence of *NO. In a similar sets of experiments, Radosevich et al $[83,84]$ have reported that when lung tumor (A549) cells were adapted to "NO following exposure to increasing concentrations of DETANONOate they showed enhanced expression of key proteins involved in non-homologous and homologous recombination pathways for DNA repair. In additions, anti-apoptotic pathways were also enhanced as shown previously [76] following prolonged "NO exposure.

Cheng et al. [85] have used various NO-donors (which mimic different intracellular exposures to ${ }^{*} \mathrm{NO}$ ) to examine gene expression profiles in order to identify genes involved in tumor response and resistance in human MDA-231 breast cells. Several genes were identified following ${ }^{*} \mathrm{NO}$ exposure, including miR-21 (upregulated in various tumors and in cardiovascular diseases), heat shock protein-90, cystathionine- $\Upsilon$-lyase and IL-24. now, however, the roles of these genes in ${ }^{*} \mathrm{NO}$-induced resistance are not known.

\section{Reversal of drug resistance by nitric oxide}

Another interesting but conflicting effect of * $\mathrm{NO}$ is that it also reverses mdr1-associated drug resistance. One of the hallmarks of mdr1 cells is that these cells overexpress p-170-glycoprotein (pgp) and multidrug resistance proteins (MRP's), which remove intracellular drugs in an energy-dependent manner. Riganti et al. [86] have described the reversal of doxorubicin resistance when induction of ${ }^{*} \mathrm{NO}$ production or delivery of * $\mathrm{NO}$ via an NO-donor inhibited efflux of doxorubicin in HT-29-dox, a doxorubicin-selected resistant cells that overexpressed pgp. It was found that increased accumulation of doxorubicin promoted by ${ }^{*} \mathrm{NO}$ was independent of the c-GMP pathway. It is interesting to note that $\mathrm{NO}$ also increased accumulation of doxorubicin in the sensitive HT-29 cells, suggesting that other mechanisms may also be involved in this. One of the mechanisms proposed to explain this reversal of resistance and increase in drug accumulation was that ${ }^{*} \mathrm{NO}$ induced significant tyrosine nitration of the MRP3 transporter protein, which was also overexpressed along with pgp during the doxorubicin resistance selection process. Some tyrosine nitration was also detected in the sensitive HT-29 cells. Furthermore, it was suggested that S-nitration of cysteines may also be involved, leading to conformational changes and modification of activity of the transporter proteins. De Boo et al. [87] have confirmed that ${ }^{*} \mathrm{NO}$-induced nitration of tyrosine in the MRP3 protein resulted in the reversal of doxorubicin resistance in K562-dx cells which overexpressed both pgp and MRP3 proteins. It is interesting to note that in this dox-resistant cell line, nitro-pgp was also detected. Additionally, De Boo et al. [87] have shown that "NO induced tyrosine nitration in pgp and MRP3 proteins in several other tumor cell lines expressing both pgp and MRP3 proteins, resulting in increased intracellular doxorubicin accumulation.

Curta et al. [88] have also shown that ${ }^{*} \mathrm{NO}$ increased the accumulation of daunorubicin (an analog of doxorubicin) in leukemia K562 cells and enhanced apoptosis in the presence of daunorubicin. K562 cells constitutively express anti-apoptotic bcl2 and survivin proteins and are resistant to daunorubicin. Treatment with an NO- 
donor in the presence of the drug decreased both bcl2 and survivin proteins, increased drug accumulation and enhanced the cytotoxicity of daunorubicin. K562 leukemia cells also overexpress both ABCC1 and lung-resistance proteins, which are a family of $\mathrm{ABC}$ transporters like pgp and MRP. While the role of lung-resistance protein overexpression in MDR is not clear, it has been shown to belong to the family of vault proteins and is involved in removing/redistributing drugs away from the nucleus $[89,90]$, thus reducing effective drug concentrations in the nucleus. Tyrosine nitration of $\mathrm{ABCC} 1$ or lung-resistant protein, resistance-related proteins expressed in K562 cells, was not studied, even though both proteins were significantly decreased during the combined treatment with an NO-donor and daunorubicin. Ishima et al. [91] have reported that poly-S-nitrosated human albumin, which may serve as a reservoir for "NO in vivo, increased doxorubicin intracellular concentration in a pgp-overexpressing K562-dx cells, resulting in the reversal of doxorubicin resistance in cells as well as in animals bearing K562-dx cells in vivo. It was found that poly-S-nitrosated albumin reversed doxorubicin resistance by decreasing the expression of pgp and HIF-1 $\alpha$ in K562-dx cells.

It has been reported that ${ }^{*} \mathrm{NO}$ formed either intracellularly or delivered via donor inhibits NF-kB activity and inactivates NF-kBregulated downstream target anti-apoptotic genes [92]. Furthermore, this inhibition also results in the inhibition of the expressions of NFkB-regulated transcription factor YY1, FAS and DR5 expressions, resulting in increased apoptosis and sensitization to various anticancer drugs. Huerta-Yepez et al. [93] have reported that high doses $(0.5 \mathrm{mM}$ to $1.0 \mathrm{mM}$ ) of DETA-NONOate sensitize resistant prostate cancer cells to cis-platin in vitro and in vivo. The NF-kB-regulated resistance factors YY1 and bclx were overexpressed in the resistant prostate cells, and it was shown that treatment with the NO-donor resulted in the inhibition of both YY1 and bclx. Combination treatment significantly enhanced cis-platin-induced apoptosis in vitro and decreased tumor growth in a xenograft model in vivo.

Studies indicate that activation of iNOS and production of * $\mathrm{NO}$ in endothelial cells induces nitration of $\beta$-catenin and its translocation to the nucleus, causing activation of NF-kB and Wnt target genes [94]. $\mathrm{Du}$ et al. [95] have shown that increased $W n t / \beta$-catenin signalling regulates iNOS gene expression through NF-kB. An increase in Wnt/ $\beta$ catenin signalling by iNOS results from the negative regulation of the Dickkof-1 (DKK-1) gene. This interplay of Wnt/signalling by iNOS has been suggested to play an important role in drug resistance in nonsmall lung tumor cells by upregulating glutathione transferase- $\pi$ and topoisomerase IIa but not pgp [96]. Insertion of DKK1 reversed this induction of GST- $\pi$ and resistance to cis-platin [96].

\section{Summary and Conclusions}

Since the discovery of ${ }^{*} \mathrm{NO}$ as the endothelial relaxing factor about 30 years ago, it has remained a most actively pursued area of research with over 100,000 publications. Currently, billions of dollars are being spent to bring ${ }^{*} \mathrm{NO}$-releasing agents to the treatment of various diseases. Many compounds, such as nitroglycerin, are available in the clinic for the treatment of acute angina. It is now very clear that ${ }^{*} \mathrm{NO}$ is also involved in cancer progression, and resistance.

It appears that ${ }^{*} \mathrm{NO}$ can be both good and bad in cancer chemotherapy. A multitude of studies and publications have now made a strong case that "NO alone can induce cell death, and that it can be combined with several important clinical anticancer drugs to enhance/ sensitize their activity against a variety of human malignancies. Efficacy and safety studies of GTN as a transdermal patch have been reported in a clinic trial against untreated stage IIIB/IV non-small cell lung cancer [97]. GTN was shown to have a positive response in combination with vinorelbine and cis-platin. Furthermore, a slowrelease transdermal GTN patch has also been shown to be effective in men with prostate tumors whose disease was progressing following surgery or radiotherapy [98].

While several NO-donors have been considered and are being utilized in the clinic to treat heart-related complications [99], none of the NO-donors whether as a single agent or in combination appears to have entered into clinical trials or been successful beyond phase I study for cancer treatment. This is not very encouraging for those of us involved in basic and translational research with "NO and NOdonors. This may, in part, be due to the fact that the biological effects of ${ }^{*} \mathrm{NO}$ are multi-factorial without any clear-cut ${ }^{*} \mathrm{NO}$ concentrations defined for the anti-cancer effects in vivo in humans. It is now well known that the actions of "NO and NO-donors are dose-dependent, as at low concentrations "NO promotes cancer cell survival, while at higher concentrations it induces DNA damage, apoptosis, and cell death. Furthermore, it is not clear how ${ }^{*} \mathrm{NO}$, can be cytotoxic to certain tumors in some cases, and in other cases, under similar conditions, it induces resistance to certain anticancer drugs by inducing bcl 2 and HIF-1a stabilization in tumor cells.

While NO-donors have been invaluable in evaluating the chemistry and biological effects of ${ }^{*} \mathrm{NO}$, it is possible that some of the controversial reported biological effects of "NO in cancer cell biology may be due to the NO-donors used. It is well known now that simple non-specific diolates, e.g. PPNO, DETA-NONOate, GSNO, spermine NONOate, and DEA-NONOate, release $\mathrm{NO}$ at physiological $\mathrm{pH}$ (and at different rates), but the biological effects of * $\mathrm{NO}$ in tumor cells are diffusion controlled. Under this scenario, "NO released outside the tumor cell must diffuse across the cell membrane to the site of action. We have found that higher concentrations of serum in the media affects the cytotoxicity of various NO-donors in tumor cells and requires higher concentrations of the NO-donors to achieve the same number of cells kill. While ${ }^{*} \mathrm{NO}$ is not extremely reactive, it does react with a variety of substrates, including glutathione, protein - $\mathrm{SH}$ and hemecenters in proteins, resulting in a significant decrease in its effective concentrations and forming other products which may also have other deleterious biological effects. Under these conditions, a given biological response is not necessarily a true measure of the concentrations of NOdonor used. In contrast, studies carried out with those NO-donors that are target specific and require intracellular activation to release ${ }^{*} \mathrm{NO}$, e.g., JS-K, the effective concentration to achieve the same biological response would be quite different as there will be significantly fewer non-specific reactions with other biological molecules. Thus, it is necessary to exercise caution in understanding and interpreting the various biological effects described in the literature using different NO-donors.

It is very intriguing that ${ }^{*} \mathrm{NO}$ can cause reversal of multidrug resistance by increasing intracellular drug concentrations in MDR/ MRP-overexpressing cells. "NO is reported to sensitize drugs to tumor cell killing under hypoxic environments. It is very important that we have a better understanding of the pathways leading to both sensitization to anticancer drugs in hypoxia and the reversal of drug resistance in cells overexpressing mdr1 and MRP proteins. Our preliminary work suggests that "NO inhibits pgp functions by inhibiting ATPase, most likely via nitrosylation of the two - $\mathrm{SH}$ groups in ATPase. It is essential to find the right "NO-delivering compound, which must also be very target specific to resistant tumor cells in the clinic. Such compounds would be ideal for the treatment of clinically resistant/or refractory tumors to successfully achieve our treatment goals. 
Citation: Sinha BK (2016) Nitric Oxide: Friend or Foe in Cancer Chemotherapy and Drug Resistance: A Perspective. J Cancer Sci Ther 8: 244-251. doi: 10.4172/1948-5956.1000421

\section{Future Directions}

Overcoming drug resistance in the clinic is a critical determinant for a successful therapy; one of the more promising directions at present is the use of NO-donors. The most successful course of action in developing cancer therapies with $\mathrm{NO}$-donors will be to develop newer ones that are site-specific to tumor cells and release "NO following intracellular activation. Not only will this significantly reduce host toxicity, but it will also increase tumor cell killing. It is anticipated that such approaches will help to define the active "NO concentrations for both cytotoxicity and development of drug resistance. Tumor-specific intracellularly activated NO-donors would also be suitable for targeting pgp/MRP-overexpressing tumor cells for the reversal of drug resistance and/or increasing tumor sensitization to chemotherapy drugs in the clinic. Since "NO acts as a catalytic inhibitor of topoisomerase II, appropriately designed NO-donors should also be developed in the future for the treatment of tumors deficient in decatenation checkpoint.

\section{Acknowledgements}

We thank Dr. Ann Motten for help in editing the manuscript. We also thank Drs. Ron Mason, Maria Kadiiska and Thomas van't Erve for their critical evaluation of the manuscript.

\section{Funding}

This research was supported [in part] by the intramural research program of the National Institute of Environmental Health Sciences, NIH. Statements contained herein do not necessarily represent the statements, opinions, or conclusions of NIEHS, NIH, or the US Government.

\section{References}

1. Endicott JA, Ling $V$ (1989) The biochemistry of P-glycoprotein-mediated multidrug resistance. Annu Rev Biochem 58: 137-171.

2. Gillet JP, Gottesman MM (2010) Mechanisms of multidrug resistance in cancer. Methods Mol Biol 596: 47-76.

3. Sinha BK, Mimnaugh EG (1990) Free radicals and anticancer drug resistance: oxygen free radicals in the mechanisms of drug cytotoxicity and resistance by certain tumors. Free Radic Biol Med 8: 567-581.

4. Saraswathy M, Gong S (2013) Different strategies to overcome multidrug resistance in cancer. Biotechnol Adv 31: 1397-1407.

5. Aas T, Børresen AL, Geisler S, Smith-Sørensen B, Johnsen H, et al. (1996) Specific P53 mutations are associated with de novo resistance to doxorubicin in breast cancer patients. Nat Med 2: 811-814.

6. Beck WT, Danks MK, Wolverton JS, Kim R, Chen M (1993) Drug resistance associated with altered DNA topoisomerase II. Adv Enzyme Regul 33: 113-127.

7. Sinha BK, Mimnaugh EG, Rajagopalan S, Myers CE (1989) Adriamycin activation and oxygen free radical formation in human breast tumor cells: protective role of glutathione peroxidase in adriamycin resistance. Cancer Res 49: $3844-3848$

8. Murad F (1998) Nitric oxide signaling: would you believe that a simple free radical could be a second messenger, autacoid, paracrine substance, neurotransmitter, and hormone?. Recent Prog Horm Res 53: 43-59.

9. Murad F (2006) Shattuck Lecture. Nitric oxide and cyclic GMP in cell signaling and drug development. N Engl J Med 355: 2003-2011.

10. Gaston B (1999) Nitric oxide and thiol groups. Biochim Biophys Acta 1411 323-333

11. Aranda E, López-Pedrera C, De La Haba-Rodriguez JR, Rodriguez-Ariza A (2012) Nitric oxide and cancer: the emerging role of S-nitrosylation. Curr Mo Med 12: 50-67.

12. Stamler JS, Lamas S, Fang FC (2001) Nitrosylation. the prototypic redoxbased signaling mechanism. Cell 106: 675-683.

13. Muntané J, la Mata MD (2010) Nitric oxide and cancer. World J Hepatol 2 337-344.

14. Hickok JR, Thomas DD (2010) Nitric oxide and cancer therapy: the emperor has NO clothes. Curr Pharm Des 16: 381-391.
15. Hirst D, Robson T (2010) Nitric oxide in cancer therapeutics: interaction with cytotoxic chemotherapy. Curr Pharm Des 16: 411-420.

16. Choudhari SK, Chaudhary M, Bagde S, Gadbail AR, Joshi V (2013) Nitric oxide and cancer: a review. World J Surg Oncol 11: 118

17. Glynn SA, Boersma BJ, Dorsey TH, Yi M, Yfantis HG, et al. (2010) Increased NOS2 predicts poor survival in estrogen receptor-negative breast cancer patients. J Clin Invest 120: 3843-3854.

18. Loibl S, Buck A, Strank C, von Minckwitz G, Roller M, et al. (2005) The role of early expression of inducible nitric oxide synthase in human breast cancer. Eur J Cancer 41: 265-271.

19. Klotz T, Bloch W, Volberg C, Engelmann U, Addicks K (1998) Selective expression of inducible nitric oxide synthase in human prostate carcinoma Cancer 82: 1897-1903.

20. Cianchi F, Cortesini C, Fantappie O, Messerini L, Schiavone N, et al. (2003) Inducible nitric oxide synthase expression in human colorectal cancer: correlation with tumor angiogenesis. Am J Pathol 162: 793-801.

21. Hibbs JB Jr, Taintor RR, Vavrin Z (1987) Macrophage cytotoxicity: role for L-arginine deiminase and imino nitrogen oxidation to nitrite. Science 235: 473-476.

22. Hibbs JB Jr, Taintor RR, Vavrin Z, Rachlin EM (1988) Nitric oxide: a cytotoxic activated macrophage effector molecule. Biochem Biophys Res Commun 157: 87-94

23. Stuehr DJ, Nathan CF (1989) Nitric oxide. A macrophage product responsible for cytostasis and respiratory inhibition in tumor target cells. J Exp Med 169 1543-1555.

24. Maragos CM, Wang JM, Hrabie JA, Oppenheim JJ, Keefer LK (1993) Nitric oxide/nucleophile complexes inhibit the in vitro proliferation of A375 melanoma cells via nitric oxide release. Cancer Res 53: 564-568.

25. Muscará MN, Wallace JL (1999) Nitric Oxide. V. therapeutic potential of nitric oxide donors and inhibitors. Am J Physiol 276: G1313-1316.

26. Huerta S, Chilka S, Bonavida B (2008) Nitric oxide donors: novel cancer therapeutics (review). Int J Oncol 33: 909-927.

27. Bonavida B, Baritaki S, Huerta-Yepez S, Vega MI, Chatterjee D, et al. (2008) Novel therapeutic applications of nitric oxide donors in cancer: roles in chemoand immunosensitization to apoptosis and inhibition of metastases. Nitric Oxide 19: 152-157.

28. Weyerbrock A, Baumer B, Papazoglou A (2009) Growth inhibition and chemosensitization of exogenous nitric oxide released from NONOates in glioma cells in vitro. J Neurosurg 110: 128-136.

29. Reynolds MM, Witzeling SD, Damodaran VB, Medeiros TN, Knodle RD, et al. (2013) Applications for nitric oxide in halting proliferation of tumor cells. Biochem Biophys Res Commun 431: 647-651.

30. Wink DA, Cook JA, Christodoulou D, Krishna MC, Pacelli R, et al. (1997) Nitric oxide and some nitric oxide donor compounds enhance the cytotoxicity of cisplatin. Nitric Oxide 1: 88-94.

31. Liu Q, Chan ST, Mahendran R (2003) Nitric oxide induces cyclooxygenase expression and inhibits cell growth in colon cancer cell lines. Carcinogenesis 24: 637-642.

32. Saavedra JE, Shami PJ, Wang LY, Davies KM, Booth MN, et al. (2000) Esterase-sensitive nitric oxide donors of the diazeniumdiolate family: in vitro antileukemic activity. J Med Chem 43: 261-269.

33. Shami PJ, Saavedra JE, Wang LY, Bonifant CL, Diwan BA, et al. (2003) JS $\mathrm{K}$, a glutathione/glutathione S-transferase-activated nitric oxide donor of the diazeniumdiolate class with potent antineoplastic activity. Mol Cancer Ther 2: 409-417.

34. Maciag AE, Chakrapani H, Saavedra JE, Morris NL, Holland RJ, et al. (2011) The nitric oxide prodrug JS-K is effective against non-small-cell lung cance cells in vitro and in vivo: involvement of reactive oxygen species. J Pharmacol Exp Ther 336: 313-320.

35. Kiziltepe T, Hideshima T, Ishitsuka K, Ocio EM, Raje N, (2007) JS-K, a GSTactivated nitric oxide generator, induces DNA double-strand breaks, activate DNA damage response pathways, and induces apoptosis in vitro and in vivo in human multiple myeloma cells. Blood 110: 709-718.

36. Shami PJ, Maciag AE, Eddington JK, Udupi V, Kosak KM, et al. (2009) JS-K an arylating nitric oxide (NO) donor, has synergistic anti-leukemic activity with cytarabine (ARA-C). Leuk Res 33: 1525-1529. 
Citation: Sinha BK (2016) Nitric Oxide: Friend or Foe in Cancer Chemotherapy and Drug Resistance: A Perspective. J Cancer Sci Ther 8: 244-251. doi: $10.4172 / 1948-5956.1000421$

37. Weyerbrock A, Osterberg N, Psarras N, Baumer B, Kogias E, et al. (2012) JS$\mathrm{K}$, a glutathione S-transferase-activated nitric oxide donor with antineoplastic activity in malignant gliomas. Neurosurgery 70: 497-510.

38. Kogias E, Osterberg N, Baumer B, Psarras N, Koentges C, et al. (2012) Growthinhibitory and chemosensitizing effects of the glutathione-S-transferase-piactivated nitric oxide donor PABA/NO in malignant gliomas. Int J Cancer 130: 1184-1194.

39. Azizzadeh B, Yip HT, Blackwell KE, Horvath S, Calcaterra TC, et al. (2001) Nitric oxide improves cisplatin cytotoxicity in head and neck squamous cell carcinoma. Laryngoscope 111: 1896-1900

40. Bratasz A, Selvendiran K, Wasowicz T, Bobko A, Khramtsov VV, et al. (2008) NCX-4040, a nitric oxide-releasing aspirin, sensitizes drug-resistant human ovarian xenograft tumors to cisplatin by depletion of cellular thiols J Transl Med 6: 9.

41. Konovalova NP, Goncharova SA, Volkova LM, Rajewskaya TA, Eremenko LT et al. (2003) Nitric oxide donor increases the efficiency of cytostatic therapy and retards the development of drug resistance. Nitric Oxide 8: 59-64.

42. Leonetti C, Scarsella M, Zupi G, Zoli W, Amadori D, et al. (2006) Efficacy of a nitric oxide-releasing nonsteroidal anti-inflammatory drug and cytotoxic drugs in human colon cancer cell lines in vitro and xenografts. Mol Cancer Ther 5 : 919-926.

43. Adams C, McCarthy HO, Coulter JA, Worthington J, Murphy C, et al. (2009) Nitric oxide synthase gene therapy enhances the toxicity of cisplatin in cancer cells. J Gene Med 11: 160-168.

44. Safdar S, Payne CA, Tu NH, Taite LJ (2013) Targeted nitric oxide delivery preferentially induces glioma cell chemosensitivity via altered p53 and O(6) -methylguanine-DNA methyltransferase activity. Biotechnol Bioeng 110: 1211-1220.

45. Adams DJ, Levesque MC, Weinberg JB, Smith KL, Flowers JL, et al. (2001) Nitric oxide enhancement of fludarabine cytotoxicity for B-CLL lymphocytes. Leukemia 15: 1852-1859.

46. Matthews NE, Adams MA, Maxwell LR, Gofton TE, Graham CH (2001) Nitric oxide-mediated regulation of chemosensitivity in cancer cells. J Natl Cancer Inst 93: 1879-1885.

47. Frederiksen LJ, Siemens DR, Heaton JP, Maxwell LR, Adams MA, et al. (2003) Hypoxia induced resistance to doxorubicin in prostate cancer cells is inhibited by low concentrations of glyceryl trinitrate. J Urol 170: 1003-1007.

48. Kumar A, Ehrenshaft M, Tokar EJ, Mason RP, Sinha BK (2016) Nitric oxide inhibits topoisomerase II activity and induces resistance to topoisomerase IIpoisons in human tumor cells. Biochim Biophys Acta 1860: 1519-1527.

49. Sinha BK, Kumar A, Bhattacharjee S, Espey MG, Mason RP (2013) Effect of nitric oxide on the anticancer activity of the topoisomerase-active drugs etoposide and adriamycin in human melanoma cells. J Pharmacol Exp Ther 347: 607-614.

50. Maxwell PH, Wiesener MS, Chang GW, Clifford SC, Vaux EC, et al. (1999) The tumour suppressor protein VHL targets hypoxia-inducible factors for oxygendependent proteolysis. Nature 399: 271-275.

51. Ivan M, Kondo K, Yang H, Kim W, Valiando J, et al. (2001) HIFalpha targeted for VHL-mediated destruction by proline hydroxylation: implications for $\mathrm{O} 2$ sensing. Science 292: 464-468.

52. Chanvorachote $P$, Nimmannit $U$, Stehlik C, Wang L, Jiang BH, et al. (2006) Nitric oxide regulates cell sensitivity to cisplatin-induced apoptosis through S-nitrosylation and inhibition of Bcl-2 ubiquitination. Cancer Res 66: 6353-6360.

53. Godoy LC, Anderson CT, Chowdhury R, Trudel LJ, Wogan GN (2012) Endogenously produced nitric oxide mitigates sensitivity of melanoma cells to cisplatin. Proc Natl Acad Sci U S A 109: 20373-20378.

54. Ridnour LA, Thomas DD, Donzelli S, Espey MG, Roberts DD, et al. (2006) The biphasic nature of nitric oxide responses in tumor biology. Antioxid Redox Signal 8: 1329-1337

55. Napoli C, Paolisso G, Casamassimi A, Al-Omran M, Barbieri M, et al. (2013) Effects of nitric oxide on cell proliferation: novel insights. J Am Coll Cardiol 62: 89-95.

56. Burke AJ, Sullivan FJ, Giles FJ, Glynn SA (2013) The yin and yang of nitric oxide in cancer progression. Carcinogenesis 34: 503-512.

57. Mateo J, Garcia-Lecea M, Cadenas S, Hernandez C, Moncada S (2003)
Regulation of hypoxia-inducible factor-1alpha by nitric oxide through mitochondria-dependent and -independent pathways. Biochem J 376: 537-544.

58. Li F, Sonveaux P, Rabbani ZN, Liu S, Yan B, et al. (2007) Regulation of HIF1alpha stability through S-nitrosylation. Mol Cell 26: 63-74.

59. Wang JC (1985) DNA topoisomerases. Annu Rev Biochem 54: 665-697.

60. Pommier Y, Leteurtre F, Fesen MR, Fujimori A, Bertrand R, et al. (1994) Cellular determinants of sensitivity and resistance to DNA topoisomerase inhibitors. Cancer Invest 12: 530-542.

61. Froelich-Ammon SJ, Osheroff N (1995) Topoisomerase poisons: harnessing the dark side of enzyme mechanism. J Biol Chem 270: 21429-21432.

62. Sinha BK (1995) Topoisomerase inhibitors. A review of their therapeutic potential in cancer. Drugs 49: 11-19.

63. Nitiss JL (2009) DNA topoisomerase II and its growing repertoire of biological functions. Nat Rev Cancer 9: 327-337.

64. Sharma NK, Kumar A, Kumari A, Tokar EJ, Waalkes MP, et al. (2015) Nitric Oxide Down-Regulates Topoisomerase I and Induces Camptothecin Resistance in Human Breast MCF-7 Tumor Cells. PLoS One 10: e0141897.

65. Sinha BK, Bhattacharjee S, Chatterjee S, Jiang J, Motten AG, et al. (2013) Role of nitric oxide in the chemistry and anticancer activity of etoposide (VP-16,213) Chem Res Toxicol 26: 379-387.

66. Deming PB, Cistulli CA, Zhao H, Graves PR, Piwnica-Worms H, et al. (2001) The human decatenation checkpoint. Proc Natl Acad Sci U S A 98: 1204412049.

67. Damelin M, Bestor TH (2007) The decatenation checkpoint. Br J Cancer 96: 201-205.

68. Nakagawa T, Hayashita Y, Maeno K, Masuda A, Sugito N, et al. (2004) Identification of decatenation G2 checkpoint impairment independently of DNA damage $\mathrm{G} 2$ checkpoint in human lung cancer cell lines. Cancer Res 64: 48264832 .

69. Chazotte-Aubert L, Hainaut $P$, Ohshima $\mathrm{H}$ (2000) Nitric oxide nitrates tyrosine residues of tumor-suppressor p53 protein in MCF-7 cells. Biochem Biophys Res Commun 267: 609-613.

70. Chazotte-Aubert L, Pluquet O, Hainaut P, Ohshima H (2001) Nitric oxide prevents gamma-radiation-induced cell cycle arrest by impairing p53 function in MCF-7 cells. Biochem Biophys Res Commun 281: 766-771.

71. Jaiswal M, LaRusso NF, Burgart LJ, Gores GJ (2000) Inflammatory cytokines induce DNA damage and inhibit DNA repair in cholangiocarcinoma cells by a nitric oxide-dependent mechanism. Cancer Res 60: 184-190.

72. Jaiswal M, LaRusso NF, Nishioka N, Nakabeppu Y, Gores GJ (2001) Human Ogg, a protein involved in the repair of 8-oxoguanine, is inhibited by nitric oxide. Cancer Res 61: 6388-6393.

73. Xu W, Liu L, Smith GC, Charles IG (2000) Nitric oxide upregulates expression of DNA-PKcs to protect cells from DNA-damaging anti-tumour agents. Nat Cell Biol 2: 339-345.

74. Azad N, Vallyathan V, Wang L, Tantishaiyakul V, Stehlik C, et al. (2006) S-nitrosylation of $\mathrm{Bcl}-2$ inhibits its ubiquitin-proteasomal degradation. A nove antiapoptotic mechanism that suppresses apoptosis. J Biol Chem 281: 3412434134.

75. Mannick JB, Schonhoff C, Papeta N, Ghafourifar P, Szibor M, et al. (2001) S-Nitrosylation of mitochondrial caspases. J Cell Biol 154: 1111-1116.

76. Wongvaranon $P$, Pongrakhananon V, Chunhacha $P$, Chanvorachote $P(2013)$ Acquired resistance to chemotherapy in lung cancer cells mediated by prolonged nitric oxide exposure, Anticancer Res 33: 5433-5444.

77. Heinecke JL, Ridnour LA, Cheng RY, Switzer CH, Lizardo MM, et al. (2014) Tumor microenvironment-based feed-forward regulation of NOS2 in breas cancer progression. Proc Natl Acad Sci U S A 111: 6323-6328.

78. Weichselbaum RR, Ishwaran H, Yoon T, Nuyten DS, Baker SW, et al. (2008) An interferon-related gene signature for DNA damage resistance is a predictive marker for chemotherapy and radiation for breast cancer. Proc Natl Acad Sci U S A. 105: 18490-18495.

79. Chapat C, Kolytcheff C, Le Romancer M, Auboeuf D, De La Grange P, et al (2013) hCAF1/CNOT7 regulates interferon signalling by targeting STAT1. EMBO J 32: 688-700. 
Citation: Sinha BK (2016) Nitric Oxide: Friend or Foe in Cancer Chemotherapy and Drug Resistance: A Perspective. J Cancer Sci Ther 8: $244-251$. doi: 10.4172/1948-5956.1000421

80. Vesper BJ, Onul A, Haines GK, Tarjan G, Xue J, et al (2013) Part I. Molecular and cellular characterization of high nitric oxide-adapted human breast adenocarcinoma cell lines. Tumour Biol 34: 203-214.

81. De Vitto H, Mendonca BS, Elseth KM, Vesper BJ, Portari EA, et al. (2013) Part II. Mitochondrial mutational status of high nitric oxide adapted cell line BT-20 (BT-20-HNO) as it relates to human primary breast tumors. Tumour Biol 34: 337-347.

82. De Vitto $\mathrm{H}$, Mendonca BS, Elseth KM, Onul A, Xue J, et al (2013) Part III. Molecular changes induced by high nitric oxide adaptation in human breast cancer cell line BT-20 (BT-20-HNO): a switch from aerobic to anaerobic metabolism. Tumour Biol 34: 403-413.

83. Aqil M, Elseth KM, Vesper BJ, Deliu Z, Aydogan B, et al. (2014) Part I-mechanism of adaptation: high nitric oxide adapted A549 cells show enhanced DNA damage response and activation of antiapoptotic pathways. Tumour Biol 35: 2403-2415.

84. Aqil M, Deliu Z, Elseth KM, Shen G, Xue J, et al. (2014) Part II-mechanism of adaptation: A549 cells adapt to high concentration of nitric oxide through bypass of cell cycle checkpoints. Tumour Biol 35: 2417-2425.

85. Cheng RY, Basudhar D, Ridnour LA, Heinecke JL, Kesarwala AH, et al. (2014) Gene expression profiles of NO- and HNO-donor treated breast cancer cells: insights into tumor response and resistance pathways. Nitric Oxide 43: 17-28.

86. Riganti C, Miraglia E, Viarisio D, Costamagna C, Pescarmona G, et al. (2005) Nitric oxide reverts the resistance to doxorubicin in human colon cancer cells by inhibiting the drug efflux. Cancer Res 65: 516-525

87. De Boo S, Kopecka J, Brusa D, Gazzano E, Matera L, et al. (2009) iNOS activity is necessary for the cytotoxic and immunogenic effects of doxorubicin in human colon cancer cells. Mol Cancer 8: 108.

88. Curta JC, de Moraes AC, Licínio MA, Costa A, Santos-Silva MC (2012) Effect of nitric oxide on the daunorubicin efflux mechanism in K562 cells. Cell Biol Int 36: 529-535

89. Dalton WS, Scheper RJ (1999) Lung resistance-related protein: determining its role in multidrug resistance. J Natl Cancer Inst 91: 1604-1605.
90. Kitazono M, Okumura H, Ikeda R, Sumizawa T, Furukawa T, et al. (2001) Reversal of LRP-associated drug resistance in colon carcinoma SW-620 cells. Int J Cancer 91: 126-131.

91. Ishima Y, Hara M, Kragh-Hansen U, Inoue A, Suenaga A, et al. (2012) Elucidation of the therapeutic enhancer mechanism of poly-S-nitrosated human serum albumin against multidrug-resistant tumor in animal models. J Control Release 164: 1-7.

92. Bonavida B, Garban H (2015) Nitric oxide-mediated sensitization of resistant tumor cells to apoptosis by chemo-immunotherapeutics. Redox Biol 6: 486-494

93. Huerta-Yepez S, Baritaki S, Baay-Guzman G, Hernandez-Luna MA Hernandez-Cueto A, et al. (2013) Contribution of either YY1 or BclXL-induced inhibition by the NO-donor DETANONOate in the reversal of drug resistance both in vitro and in vivo. YY1 and BcIXL are overexpressed in prostate cancer. Nitric Oxide 29: 17-24.

94. Gonzalez D, Rojas A, Herrera MB, Conlan RS (2012) iNOS activation regulates $\hat{i}^{2}$-catenin association with its partners in endothelial cells. PLoS One 7: e52964.

95. Du Q, Zhang X, Liu Q, Zhang X, Bartels CE, et al. (2013) Nitric oxide production upregulates $\mathrm{Wnt} / \mathrm{I}^{2}$-catenin signaling by inhibiting Dickkopf-1. Cancer Res 73 : 6526-6537.

96. Li Y, Ma C, Shi X, Wen Z, Li D, et al. (2014) Effect of nitric oxide synthase on multiple drug resistance is related to Wnt signaling in non-small cell lung cancer. Oncol Rep 32: 1703-1708.

97. Yasuda H, Yamaya M, Nakayama K, Sasaki T, Ebihara S, et al. (2006) Randomized phase II trial comparing nitroglycerin plus vinorelbine and cisplatin with vinorelbine and cisplatin alone in previously untreated stage IIIB/IV nonsmall-cell lung cancer. J Clin Oncol 24: 688-694.

98. Siemens DR, Heaton JP, Adams MA, Kawakami J, Graham CH (2009) Phase II study of nitric oxide donor for men with increasing prostate-specific antigen level after surgery or radiotherapy for prostate cancer. Urology 74: 878-883.

99. Miller MR, Megson IL (2007) Recent developments in nitric oxide donor drugs. Br J Pharmacol 151: 305-321. 